\title{
Prognostic Significance of CD31 Expression in Patients with Non-Small-Cell-Lung Cancer
}

\author{
Alexander Emmert1 ${ }^{* \#}$, Angelika Oellerich ${ }^{1 \#, ~ L a s z l o ~ F u ̈ z e s i ' ~}{ }^{2}$, Regina Waldmann-Beushausen ${ }^{1}$, \\ Hanibal Bohnenberger ${ }^{2}$, Friedrich A. Schöndube ${ }^{1}$, Bernhard C. Danner ${ }^{1}$
}

${ }^{1}$ Department of Thoracic and Cardiovascular Surgery, University of Göttingen, Göttingen, Germany

${ }^{2}$ Department of Pathology, University of Göttingen, Göttingen, Germany

Email: *alexander.emmert@med.uni-goettingen.de

How to cite this paper: Emmert, A., Oellerich, A., Füzesi, L., Waldmann-Beushausen, R., Bohnenberger, H., Schöndube, F.A. and Danner, B.C. (2016) Prognostic Significance of CD31 Expression in Patients with Non-Small-Cell-Lung Cancer. $A d$ vances in Lung Cancer, 5, 21-29.

http://dx.doi.org/10.4236/alc.2016.53003

Received: August 10, 2016

Accepted: September 19, 2016

Published: September 22, 2016

Copyright $\odot 2016$ by authors and Scientific Research Publishing Inc. This work is licensed under the Creative Commons Attribution International License (CC BY 4.0).

http://creativecommons.org/licenses/by/4.0/

\begin{abstract}
Non-small cell lung cancer (NSCLC) is the primary cause of cancer related death worldwide. After resection of early stage NSCLC, the benefit of adjuvant chemotherapy for patient survival still remains unclear and investigations for further risk stratification are needed for an improved treatment decision. Microvessel density (MVD) influences both the nutrition of the cancer and the access to the bloodstream for the development of distant metastasis. The aim of this study was to examine the prognostic significance of microvessel density by CD31 staining in patients with resected stage IA-IIIB NSCLC. We used immunohistochemistry (IHC) of CD31 to examine the microvessel density in a cohort of 69 patients who had undergone radical resection for NSCLC. Correlation of IHC values and standard clinicopathologic parameters was analyzed as well as influence on long term survival. Survival analysis revealed a significant better overall survival for patients with higher median microvessel density ( $\log$ rank $\mathrm{p}=0.031)$ independent of clinicopathologic parameters. Regarding primary cancer related death, the survival was again significantly longer in patients with high CD31 count ( $\log$ rank $\mathrm{p}=0.036$ ). A higher microvessel density was a strong predictor for a longer tumor related survival and could be used for therapeutic decisions of adjuvant chemotherapy after resection of early stage NSCLC.
\end{abstract}

\section{Keywords}

NSCLC, CD-31, Neoangiogenesis

\section{Background}

Lung cancer is a major global health problem and is the leading cause of cancer related \#Alexander Emmert and Angelika Oellerich contributed equally to this work. 
death in several countries. Non-small-cell lung cancer (NSCLC) is a particularly devastating form of lung cancer, with an overall five-year mortality of $11 \%-16 \%$. The strongest predictors of mortality are TNM classification and the completeness of surgical resection. It is characterized by uncontrolled growth and spread of abnormal cells by tumour neoangiogenesis [1]. In health, neoangiogenesis is the growth of new blood vessels, e.g., into injured tissue and is an important process governed by intricate control mechanisms, which varies depending on physiological circumstances. However, in human cancers, successful tumor growth and development also relies on neoangiogenesis and understanding the underlying molecular mechanisms of neoangiogenesis is an important step in combating NSCLC [2]. The intensity of neoangiogenesis in a tumor can be reliably evaluated by measuring the intratumoral microvessel density (MVD) by immunohistochemically staining of CD31 cell membrane protein, also known as PECAM-1 (Platelet Endothelial Cell Adhesion Molecule-1). Weighing 130 $\mathrm{kDa}, \mathrm{CD} 31$ is integral membrane protein of endothelial cells and a member of the immunoglobulin superfamily, which mediates cell-to-cell adhesion [3]. It is expressed on both adult and embryonic endothelial cells [3].

Using immunohistochemical techniques and multivariate analysis, we set out to investigate whether intratumoral microvessel density (MVD) reflected by CD31 staining, could provide prognostic information in NSCLC patients. The correlation between CD31, as well as the prognostic importance of the relationship between MVD and the clinical pathological features of stage I-III NSCLC after radical surgery was also analysed.

\section{Methods}

\subsection{Inclusion Criteria}

After obtaining local ethical committee approval and written patient informed consent and once complete tumour staging had been carried out; patients to undergo radical surgery for stage IA-III NSCLC, including adenocarcinoma (ADC) and squamous cell carcinoma (SCC) were included. In addition, none of the patients had received prior chemo or radiation therapy. Pathological staging of each tumour was determined using the renewed TNM staging system for NSCLC [4]. All procedures were conducted in accordance with institutional, state and federal guidelines and WHO classification was used for histological assessment of each specimen.

\subsection{Patients and Samples}

A total of 69 consecutive patients, who underwent radical surgical resection in the year 2006at our thoracic surgery department were included in this retrospective study. Preoperative interdisciplinary tumour board meetings were held and proposed curative resection surgery for each patient included. No other previous or concomitant primary cancer was present. Histological types of lung cancer included: ADC in 27 patients (39.1\%), and SCC in 42 patients (60.9\%). Table 1 summarizes further clinical characteristics. 
Table 1. Clinical characteristics.

\begin{tabular}{|c|c|c|}
\hline Characteristics & $\operatorname{ADC}(\mathrm{n}=27)$ & $\operatorname{SCC}(n=42)$ \\
\hline Age (years) & $63.55 \pm 10.8$ & $66.2 \pm 7.7$ \\
\hline Gender & $\begin{array}{l}20 \text { male }(74.1 \%) \\
7 \text { female }(25.9 \%)\end{array}$ & $\begin{array}{c}41 \text { male }(97.6 \%) \\
1 \text { female }(2.4 \%)\end{array}$ \\
\hline Operation type & $\begin{array}{c}\text { Pneumectomy: } 3(11.1 \%) \\
\text { Lobectomy: } 22(81.5 \%) \\
\text { Bilobectomy: } 2(7.4 \%)\end{array}$ & $\begin{array}{c}\text { Pneumectomy: } 10(23.8 \%) \\
\text { Lobectomy: } 27(64.3 \%) \\
\text { Bilobectomy: } 5(11.9 \%)\end{array}$ \\
\hline Lymphnodes resected (n) & $17.8 \pm 6.8$ & $20.9 \pm 8.6$ \\
\hline $\begin{array}{l}\text { Pathologic Stage } \\
\text { (7th edition) }\end{array}$ & $\begin{array}{c}\text { IA: } 3(11.1 \%) \\
\text { IB: } 13(48.1 \%) \\
\text { IIA: } 1(3.7 \%) \\
\text { IIB: } 4(14.8 \%) \\
\text { IIIA: } 6(22.2 \%)\end{array}$ & $\begin{array}{c}\text { IA: } 3(7.1 \%) \\
\text { IB: } 12(28.6 \%) \\
\text { IIA: } 9(21.4 \%) \\
\text { IIB: } 8(19.0 \%) \\
\text { IIIA: } 9(21.4 \%) \\
\text { IIIB: } 1(2.4 \%)\end{array}$ \\
\hline T-Status & $\begin{array}{c}\text { T1a: } 17(18.5 \%) \\
\text { T1b: } 6(22.2 \%) \\
\text { T2a: } 10(37.0 \%) \\
\text { T2b: } 4(14.8 \%) \\
\text { T3: } 2(7.4 \%)\end{array}$ & $\begin{array}{c}\text { T1a: } 3(7.1 \%) \\
\text { T1b: } 7(16.7 \%) \\
\text { T2a: } 13(31.0 \%) \\
\text { T2b: } 9(21.4 \%) \\
\text { T3: } 7(16.7 \%) \\
\text { T4: } 3(7.1 \%)\end{array}$ \\
\hline N-Status & $\begin{array}{c}\text { N0: } 17(63 \%) \\
\text { N1: } 16(14.8 \%) \\
\text { N2: } 6(22.2 \%)\end{array}$ & $\begin{array}{c}\text { N0: } 27(64.3 \%) \\
\text { N1: } 9(21.4 \%) \\
\text { N2: } 5(11.9 \%) \\
\text { N3: } 1(2.4 \%)\end{array}$ \\
\hline Grading & $\begin{array}{c}1^{\circ} \text { Grade: } 1(3.7 \%) \\
2^{\circ} \text { Grade: } 17(63.0 \%) \\
3^{\circ} \text { Grade: } 9(33.3 \%)\end{array}$ & $\begin{array}{l}2^{\circ} \text { Grade: } 28(66.7 \%) \\
3^{\circ} \text { Grade: } 14(33.3 \%)\end{array}$ \\
\hline Mean follow up time (month) & $35 \pm 27.9$ & $51.5 \pm 35.9$ \\
\hline
\end{tabular}

A structured follow up questionnaire was sent to oncologists, pulmonary physician sand general practitioners.

\subsection{Histological Evaluation of Microvessel Density}

Tumor tissues from each lung cancer specimen were fixed in $4 \%$ buffered formalin and embedded in paraffin. Immunohistochemical reactions were performed on $2 \mu \mathrm{m}$ tissue sections. Following deparaffinization and rehydration the sections were incubated in target Retrival Solution, pH low (Dako, Hamburg, Germany) for $40 \mathrm{~min}$ at $90^{\circ} \mathrm{C}$. Thereafter the samples were incubated for 15 min with $3 \% \mathrm{H}_{2} \mathrm{O}_{2}$ (Dako) to block endogenous peroxidase activity. For primary antibodies the sections were incubated for overnight at $4^{\circ} \mathrm{C}$ temperature with the monoclonal antibody JC70A diluted at 1:30 (Dako). Thereafter the sections were incubated with a two-step indirect streptavidinbiotin secondary antibody system coupled to HRPO peroxidase (Dako). DAB (Dako) was applied to visualize the sites of immunoprecipitations. Tissue samples were analyzed by light microscopy after counterstaining with Meyer's haematoxylin.

Recommendations of Weidner were followed to assess MVD [5]. In three regions 
with highest expression of CD31, 25× magnification was used to determine hotspots (Figure 1). Once hotspots were identified, areas of CD31 were counted at a magnification of $\times 100$ by two separate investigators. A total of 828 fields were analysed (12 per patient).

\subsection{Data Analysis}

Clinicopathologic standard parameters including gender, histopathology, UICC and pT stage, lymph node status, and grading were analyzed with regard to the findings of immunohistochemistry. Categorical variables were expressed as proportions (\%) or number ( $\mathrm{n}$ ) and continuous variables as mean \pm standard deviation (SD) and median with range. Long-term follow-up (survival or lung cancer related death at 90 days after surgery) was determined by the Kaplan-Meier method, differences between groups were tested with the log rank test and Cox Regression $t$ influence of clinicopathologic parameters analysis was used. Association analysis for linear correlation of median CD31 values was given as Pearson's correlation coefficient, whereas Kendall tau-b correlation coefficient $\mathrm{T}$ was provided for correlation with clinicopathologic parameters. Results were considered significant for $\mathrm{p}$ values below 0.05 . Long term follows up, defined as survival or death after 90 days postoperative could be fully completed. To test the influence of CD-31 expression on long-term survival, all patients with known lung cancer death or living were studied. Statistical modelling and testing were performed with SPSS ${ }^{\circledast}$ statistical software (Release 15.0.0).

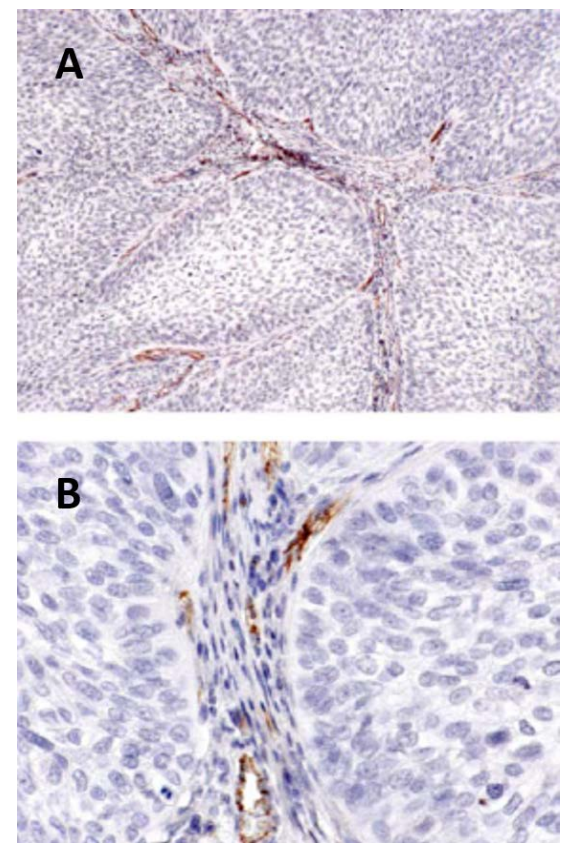

Figure 1. CD31 staining of lung tissue sample. An exemplary CD31 immunostaining that was used for determination of the microvessel density is shown in magnification of $25 \times(\mathrm{A})$ and $100 \times$ (B). Staining of CD31 was carried out using monoclonal antibody JC70A respectively. 


\section{Results}

\subsection{Socio-Demographic and Clinical Characteristics of Included Patients}

Our study included 69 consecutive patients, who had undergone surgical treatment at our institution. The socio-demographic and clinical characteristics of the patients are described in Table 1.

\subsection{Histological Assessment of MVD}

A total of 69 patients with available NSCLC tumor tissue blocks were included in the analysis of microvessel density (MVD), of these 27 with an adenocarcinoma and 42 with a squamous cell lung cancer. After immunohistochemical staining of CD31 in the tissue sections, the MVD was counted according to the recommendations of Weidner et al. For this purpose, two independent investigators first determined hotspots with highest expression of CD31 at a magnification of $25 \times$ and then counted CD31 positive cells in a total of 828 fields (12 per patient) at a magnification of $100 \times$. Figure 1 shows an example of a CD31 staining that was used for determination of MVD.

The range of MVD in all tissue samples was 18 - 454, with a median of 135 and a mean of 147. The MVD showed no statistically significant correlation to the clinicopathologic parameters. Especially there was no correlation to pathologic staging.

\subsection{Correlation of MVD to Clinical Data}

All patients were included in the analysis of overall survival at a mean follow-up of 48 months. At the time of last follow-up 25 patients were alive (36.2\%). Overall median survival time was 45 month. Lung cancer related death occurred in 33 patients (47.8\%), for unknown reasons in $6(8.7 \%)$, due to a secondary tumor in $1(1.4 \%)$, and for other non-tumorous reasons in 4 patients (5.8\%).

The analysis survival revealed a significantly improved overall survival associated with higher CD31 count. The MVD of 29 patients (42\%) exceeded the median of 135 and in this group overall survival was significantly better compared to patients with MVD below median (78 \pm 10 versus $52 \pm 8$ months, log rank $\mathrm{p}=0.031)$. In 58 patients (84\%), the cause of death was identified as primarily cancer related. In this cohort a MVD above the median was equally present in $44.2 \%$ of cases (26 patients) and survival was significant longer in patients with high MVD $(83 \pm 10$ versus $56 \pm 10$ months, log rank $\mathrm{p}=0.036)$. Kaplan Meier survival curve for cancer related death is shown in Figure 2. After Cox-Regression analysis MVD higher than the median level was identified as an independent factor for survival.

\section{Discussion}

In this retrospective study we evaluated the prognostic value of CD31 immunostaining and microvessel density in patients with resected NSCLC of stage IA-III.

In 1989, Folkman hypothesised that tumor growth is dependent on successful angiogenesis and that methods that inhibit angiogenesis could be integrated into tumor 


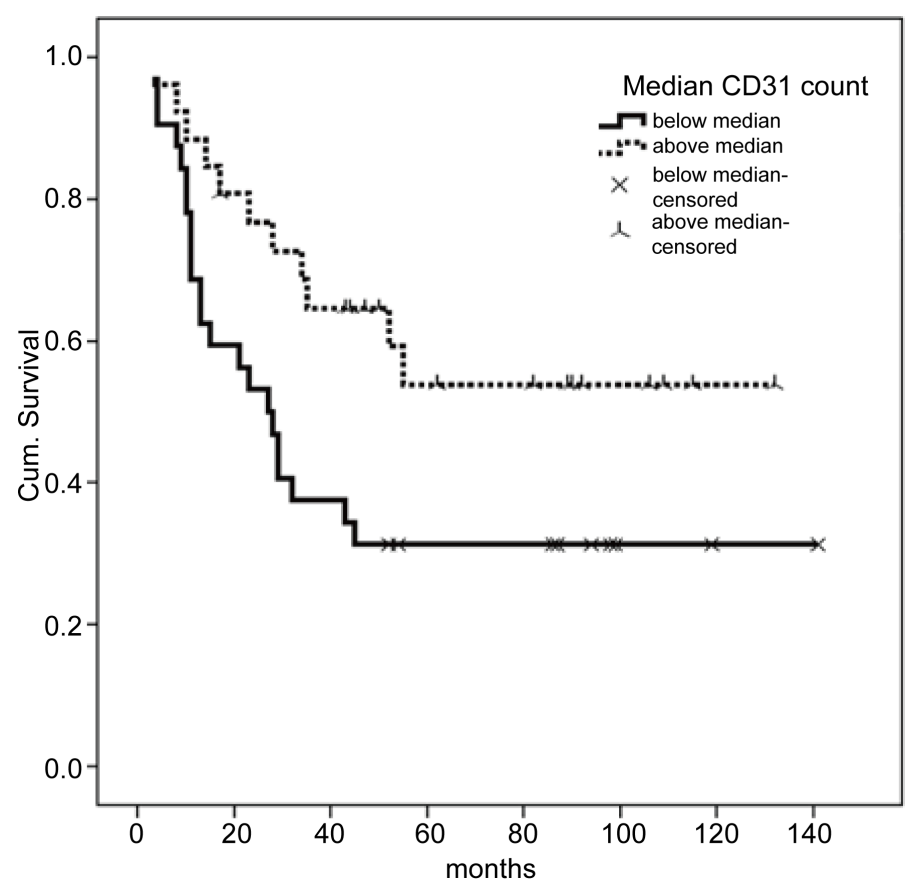

Figure 2. Survival analysis for cancer related death. The Kaplan-Meier survival curve shows cancer related survival in dependency of microvessel density. The MVD of 26 patients (44.2\%) was above and of 32 patients (55.8\%) was below the median MVD of 135 .

therapy [2]. Strong evidence has since been provided supporting this hypothesis [6]-[9]. Neoangiogenesis is a complex phenomenon and solid tumors cannot grow beyond $1-2$ $\mathrm{mm}$ in diameter without neoangiogenesis [8]. Expanding evidence suggests that neoangiogenesis is also an integral part of tumor cell dissemination and propensity for metastasize [10] [11]. Therefore detailed assessment of neoangiogenesis in tumors could not only lead to the development of new improved anti-angiogenic therapies, but also provide information that could help stratify patients into different treatment regimens and potentially predict response to chemotherapy [10] [11]. Microvessel density (MVD) in tumor samples can be identified by immunhistochemial staining of CD31. Indeed, CD31 is widely considered to be the most sensitive marker and anti-CD31 monoclonal antibody could be regarded as the standard for MVD assessment [12]. Despite the subject being investigated for several years, the use of angiogenesis (reflected by MVD) as marker for prognosis in the NSCLC remains unclear. Although some studies looking at survival rates have identified neoangiogenesis as a predictor of poor long term survival in lung cancer patients, other studies show that MVD itself does not correlate with clinicopathologic parameters and long term survival [13] [14].

In this study we have shown that MVD assessed by CD31 staining in NSCLC patients did not show a correlation to histology or histopathological staging. However, we found a statistically significant increased cancer specific overall survival in patients with a higher CD31 count area. Particularly in patients with squamous cell carcinoma, was a high CD31 expression associated with better prognosis. The reasons for this seemingly 
paradoxical finding are not exactly clear and significant limitations to this study include that it is a retrospective study and that only patients who underwent surgery were included. However this relationship was also reported in a prior meta-analysis of seven studies looking at MVD in lung cancer [11]. Studies on the relationship of MVD and prognosis of NSCLC are few in number and have showed inconsistent results, which might be due to differing selection criteria of patients and non-uniform methods used to stain and count microvessels (e.g. different antibody clones, identification of 'hotspots', Weidner or Chalkey counting method, cut-off selection) [8] [11]. Although, studies on the relationship of MVD and CD31 expression (particularly in NSCLC) are few in number more standardized methods of assessing MVD should be agreed upon, if studies are to be compared and reliable conclusions drawn [15].

Nonetheless, although CD31 expression may not appear to be useful indicators of prognosis, they still could be of clinical importance. The past few years have seen rapid development and improvement of tumor inhibitors, and an increasing body of evidence suggests that selective inhibitors of growth factors (e.g. EGFR) provide useful therapeutic agents, particularly in advanced NSCLC.

\section{Conclusion}

In conclusion, we found NSCLC patients with higher CD31 values had improved longterm survival. Significant limitations to this study include that it is a retrospective study and that only patients who have underwent surgery are included. Additionally, although our findings may appear surprising or even paradoxical, previous studies on MVD have also been controversial and unequivocal. Nevertheless, even though studies on the subject continue to yield seemingly contradictory results, the role of these factors in antitumor therapy should continue to be researched and perhaps standardised prospective studies will elucidate matters.

\section{Conflict of Interest}

The authors declare that they have no conflict of interest.

\section{Contributions}

$\mathrm{AE}, \mathrm{BCD}, \mathrm{AO}$ and FAS conceived of the study and participated in its design. AO, AE, $\mathrm{HB}$ and FAS participated in the design of the study and performed the statistical analysis. $\mathrm{AO}, \mathrm{HB}$ and RWB participated in the interpretation of the pathologic data and critical reviewing of the manuscript. $\mathrm{AE}, \mathrm{AO}$ and $\mathrm{BCD}$ drafted the manuscript. All authors read and approved the final manuscript.

\section{Acknowledgements}

Hanibal Bohnenberger was supported by the Else-Kröner-Fresenius-Foundation.

We acknowledge support by the German Research Foundation and the Open Access Publication Funds of the Göttingen University. 


\section{References}

[1] Hanahan, D. and Folkman, J. (1996) Patterns and Emerging Mechanisms of the Angiogenic Switch during Tumorigenesis. Cell, 86, 353-364.

http://dx.doi.org/10.1016/S0092-8674(00)80108-7

[2] Folkman, J. (1989) What Is the Evidence That Tumors Are Angiogenesis Dependent? Journal of the National Cancer Institute, 82, 4-6.

[3] DeLisser, H.M., Christofidou-Solomidou, M., Strieter, R.M., Burdick, M.D., Robinson, C.S., Wexler, R.S., Kerr, J.S., Garlanda, C., Merwin, J.R., Madri, J.A. and Albelda, S.M. (1997) Involvement of Endothelial PECAM-1/CD31 in Angiogenesis. The American Journal of Pathology, 151, 671-677.

[4] Detterbeck, F.C., Boffa, D.J. and Tanoue, L.T. (2009) The New Lung Cancer Staging System. Chest, 136, 260-271. http://dx.doi.org/10.1378/chest.08-0978

[5] Weidner, N., Semple, J.P., Welch, W.R. and Folkman, J. (1991) Tumor Angiogenesis and Metastasis-Correlation in Invasive Breast Carcinoma. The New England Journal of Medicine, 324, 1-8. http://dx.doi.org/10.1056/NEJM199101033240101

[6] Ribatti, D. and Vacca, A. (2008) The Role of Microenvironment in Tumor Angiogenesis. Genes \& Nutrition, 3, 29-34. http://dx.doi.org/10.1007/s12263-008-0076-3

[7] Koukourakis, M.I., Giatromanolaki, A., Skarlatos, J., Corti, L., Blandamura, S., Piazza, M., Gatter, K.C. and Harris, A.L. (2001) Hypoxia Inducible Factor (HIF-1a and HIF-2a) Expression in Early Esophageal Cancer and Response to Photodynamic Therapy and Radiotherapy. Cancer Research, 61, 1830-1832.

[8] Meert, A.P., Paesmans, M., Martin, B., Delmotte, P., Berghmans, T., Verdebout, J.M., Lafitte, J.J., Mascaux, C. and Sculier, J.P. (2002) The Role of Microvessel Density on the Survival of Patients with Lung Cancer: A Systematic Review of the Literature with MetaAnalysis. British Journal of Cancer, 87, 694-701. http://dx.doi.org/10.1038/sj.bjc.6600551

[9] Vermeulen, P.B., Libura, M., Libura, J., O’Neill, P.J., van Dam, P., Van Marck, E., Van Oosterom, A.T. and Dirix, L.Y. (1997) Influence of Investigator Experience and Microscopic Field Size on Microvessel Density in Node-Negative Breast Carcinoma. Breast Cancer Research and Treatment, 42, 165-172. http://dx.doi.org/10.1023/A:1005737524541

[10] Chandrachud, L.M., Pendleton, N., Chisholm, D.M., Horan, M.A. and Schor, A.M. (1997) Relationship between Vascularity, Age and Survival in Non-Small-Cell Lung Cancer. British Journal of Cancer, 76, 1367-1375. http://dx.doi.org/10.1038/bjc.1997.562

[11] Fontanini, G., Lucchi, M., Vignati, S., Mussi, A., Ciardiello, F., De Laurentiis, M., De Placido, S., Basolo, F., Angeletti, C.A. and Bevilacqua, G. (1997) Angiogenesis as a Prognostic Indicator of Survival in Non-Small-Cell Lung Carcinoma: A Prospective Study. Journal of the National Cancer Institute, 89, 881-886. http://dx.doi.org/10.1093/jnci/89.12.881

[12] Zhou, D., Cheng, S.Q., Ji, H.F., Wang, J.S., Xu, H.T., Zhang, G.Q. and Pang, D. (2010) Evaluation of Protein Pigment Epithelium-Derived Factor (PEDF) and Microvessel Density (MVD) as Prognostic Indicators in Breast Cancer. Journal of Cancer Research and Clinical Oncology, 136, 1719-1727. http://dx.doi.org/10.1007/s00432-010-0830-y

[13] Stellmach, V., Crawford, S.E., Zhou, W. and Bouck, N. (2001) Prevention of Ischemia- Induced Retinopathy by the Natural Ocular Antiangiogenic Agent Pigment Epithelium- Derived Factor. Proceedings of the National Academy of Sciences of the United States of America, 98, 2593-2597.

[14] Jiang, Y., Goldberg, I.D. and Shi, Y.E. (2002) Complex Roles of Tissue Inhibitors of Metalloproteinases in Cancer. Oncogene, 21, 2245-2252. 
http://dx.doi.org/10.1038/sj.onc.1205291

[15] Hase, R., Miyamoto, M., Uehara, H., Kadoya, M., Ebihara, Y., Murakami, Y., Takahashi, R., Mega, S., Li, L., Shichinohe, T., Kawarda, Y. and Kondo, S. (2005) Pigment Epithelium- Derived Factor Gene Therapy Inhibits Human Pancreatic Cancer in Mice. Clinical Cancer Research, 11, 8737-8744. http://dx.doi.org/10.1158/1078-0432.CCR-05-1323

\section{Abbreviations}

CD31: Cluster of Differentiation 31

H\&E: Hematoxylin-Eosin Staining

IHC: Immunohistochemistry

NSCLC: Non-Small Cell Lung Cancer

MVD: Microvessel Density

PECAM-1: Platelet Endothelial Cell Adhesion Molecule-1

SD: Standard Deviation

\section{Submit or recommend next manuscript to SCIRP and we will provide best service} for you:

Accepting pre-submission inquiries through Email, Facebook, LinkedIn, Twitter, etc. A wide selection of journals (inclusive of 9 subjects, more than 200 journals)

Providing 24-hour high-quality service

User-friendly online submission system

Fair and swift peer-review system

Efficient typesetting and proofreading procedure

Display of the result of downloads and visits, as well as the number of cited articles

Maximum dissemination of your research work

Submit your manuscript at: http://papersubmission.scirp.org/

Or contact alc@scirp.org 